\title{
Race, Education and Positive Perception towards Mental Health Treatments
}

\author{
Phu Phan, MSW, Ph.D. (Corresponding author) \\ Human Services \\ California State University Dominguez Hills \\ 1000 E. Carson St., Carson, CA 90747, USA \\ E-mail: pphan@csudh.edu
}

Kaipeng Wang, MSW

Boston College Graduate School of Social Work

McGuinn Hall 205, Chesnut Hill, MA 02467, USA

Thanh V. Tran, Ph.D.

Boston College Graduate School of Social Work

McGuinn Hall 205, Chesnut Hill, MA 02467, USA

Received: March 25, 2015 Accepted: April 24, 2015 Published: April 29, 2015

doi:10.5296/ijssr.v3i2.7310 URL: http://dx.doi.org/10.5296/ijssr.v3i2.7310

\begin{abstract}
This paper explores the relationship between race, education, and positive perception toward mental health treatments. It utilizes the 2012 Behavioral Risk Factor Surveillance System (BRFSS) and analyzes the responses of 93,896 adult respondents from 5 racial groups: American Indians, Asians, Blacks, Hispanics, and Whites. Results reveal that race influences people's positive perception towards mental health treatments, and education moderates the association between race and positive perception towards mental health treatments. For effective public mental health education and intervention program developments, future studies should explore public attitudes toward specific types of mental health treatments.
\end{abstract}


Keywords: education, race, positive mental health perceptions, mental health treatments, mental health education; mental health prevention

\section{Introduction}

Public perception towards mental health services is important for both patients and providers. People who have negative perception of mental health services are less likely to seek services. Similarly, public health professionals who have negative perception towards mental health treatments are less likely to recommend mental health treatments for their clients or patients.

There continues to be disparities in mental health services and treatments between minorities and whites (Cook et al., 2014; USDHHS, 1999). Indeed, compared to non-Latino whites, blacks and Latinos access mental health care at half the rate (Cook et al., 2014). Research has shown a relationship between stigma, a person's race, his/her perception, and actual mental health outcomes (Manson, 2004). However, what exactly the connection is less well-studied. In the U.S., underutilization of mental health treatments due to stigma is well documented (USDHHS, 2001). This paper examines the relationship between race, education, and positive perception toward mental health treatment between white Americans, African Americans, Native Americans, Asian Americans, and Latino Americans.

\section{Literature Review}

\subsection{Stigma and Mental Health}

Stigma remains the most important factor in the underutilization of mental health services in the U.S. (USDHHS, 1999; USDHHS, 2001). The origin of stigma in mental illness can be traced back to Descartes who conceptualized the distinction between the "mind" and the "body," hence ushering in the separate concepts of "mental” and "physical” health (USDHHS, 1999). Stickney, Yanosky, Black, and Stickney (2012) argued that to increase mental health service utilization, it would be worthwhile for America to put resources into decreasing stigma. Overall, women were found to be less stigmatized than men (USDHHS, 1999). In addition, the perception of the controllability of mental health condition was positively associated with increased stigma, and African Americans and Hispanics were found to be less stigmatizing toward those with mental illness than Asian Americans and Caucasian (Stickney, Yanosky, Black, \& Stickney, 2012). Stigma is directly related to the perception of mental illness and mental health service utilizations. It is also a big concern with older people regarding loss of cognitive functions, such as memory (Laditak et al., 2011). Krol (2011) studied the relationship of culture and the stigma of mental illness from African American, Hispanic, Asian, and Caucasian college students and found that they all had stigmatizing attitudes toward consumers of mental health; that these consumers are blamed for their illness; and that these college students are leery of the fact that patients might recover from it, including believing that people should be coerced into treatments. These attitudes and perceptions were corroborated and were common themes in one of the largest research of American public opinion on this topic (Pescosolido et al., 1999). 


\subsection{Other Socioeconomic Factors and Mental Health}

In addition to stigma, other factors affect the rate of underutilization of mental health services. Ethnic identify, immigration and acculturation, discrimination, low socioeconomic status, lack of good employment opportunities, language acquisition, worldview, and having access to insurance are among other factors that affect the mental health of the U.S. populations (Lopez, 2009). Studies have documented that Latino, African American, and Asian/Pacific Islander American children are underserved by mental health system in relationship to non-Hispanic whites (Daley, 2005). Pote and Orrell (2002) argues that although the concept of mental health encompasses different meanings for people around the world, as it is practiced today, psychiatry has Western orientation and roots, therefore, for people from nonwestern cultures and backgrounds, there is incongruency. Indeed, Pote and Orrell find that including race, other factors such as gender, religion and educational attainment were also influential in how schizophrenia was perceived in Britain. This finding contradicts with earlier findings by Sue, Wagner, Ja, Margullis, and Lew (1976) who found that ethnicity accounted for only a small proportion of the variance in conception of mental health between Asian American and Caucasian students.

Tanebaum (2009) found that poverty and powerlessness were associated with contentious relationships between consumers and their public sector psychiatrist. Georgiades, Boyle and Fife (2013) found that immigrant and racial/ethnic congruence in school has a negative association with emotional and behavioral problems for non-Hispanic whites, Hispanics, and Native Americans. Belongingness in high-value social group is also a factor (Nakashima, Isobe, \& Ura, 2013) that mediates one’s mental health.

To understand the issue of mental health and one's perception, researchers have used the explanatory model to understand a personal belief system about illnesses (Kleinman, 1976). This explanatory model refers to five areas: etiology, time and mode of symptom onset, pathophysiology, course of sickness, and treatments. In these five areas, the clinician asks the patient questions to understand his/her perception (therefore, explanation) of the illness. This framework has since been incorporated since the publication of the DSM-IV as part of the recommended practice for establishing cultural factors that may be associated with psychiatric illnesses and it holds promise for improved services delivery and outcomes for clients (Daley, 2005). Using the explanatory framework, we present the research on race and mental health perception and treatments on the major groups of people in the U.S. today.

\subsection{White Americans}

Stigma continues to be the factor that drives underutilization of mental health services for white Americans (USDHHS, 1999). Composing of 74.8\% of the population (Census, 2010e), white Americans measure better in every aspects of mental health than other ethnic groups (USDHHS, 1999). However, it is interesting that a search of "white" or "Caucasian Americans" and "perceptions of mental illness" only yielded results on how ethnic minorities view mental illness, and little research on Caucasian Americans' views. One of the often-cited sources of Americans' perception to mental illness is the Surgeon General's report (USDHHS, 1999) on mental illness, in which the words "Americans" and "ethnic-Americans" are used, 
apparently to distinguish white and ethnic Americans, this distinction is more pronounced by having a separate supplement report on mental health in which "culture, race, and ethnicity was addressed” (USDHHS, 2001). Therefore, for lack of information specifically on whites, this section will use the terms "white Americans" to replace "American” (as used in the Surgeon General's report) since we think it is a better, more descriptive word, since other ethnic Americans are also Americans.

Overtime, perceptions of mental illness in America has been stable, but have improved somewhat. However, the early distinction between "physical" and "mental health" are still strong in America. Early on, mental illness was seen as witchcraft, and/or" something that the feeble-minded get. Over time, the Americans public has come to understand it in a more scientific way. One of the largest studies on American public's perceptions about mental illness was performed by Pescosolido et al. (1999). These researchers surveyed the American public as part of the General Social Survey and found that most American's concept of mental illness is much broader now than in the 1950s, when the first such report came out (Shirley Start's first national survey, cited by Pescosolido et al., 1999). However, in the American public's view, the mentally ill is still perceived to be of those who are violent and/or dangerous. This perception of the mentally ill is harshest for those suffering from schizophrenia and substance use, although women are seen as less violent than men. Stigma about mental illness is deeply ingrained in the American psyche. However, for white Americans, when faced with an impending nervous breakdown, the most common response was to seek formal healthcare. They are more likely to rely on prescriptions and mental health professionals, and if treated, mental health problems will improve, but first, they would turn to families and friends for help and support. White Americans believe that legal means should be used to force hospitalization, and it's the individual's responsibility to get treated, and there is a preference for social distance between the public and those with mental health problems. The power of stigma is still so strong regarding mental illness, so much that white Americans are also least likely to accept people with psychological problems as family members (Pescosolido et al., 1999; USDHHS, 1999).

\subsection{African Americans}

As of the 2010 Census, African Americans make up of 13.6\% of the U.S. population (Census, 2010b). For African Americans, as with other ethnic groups, stigma has been identified as the most significant barrier in accessing mental health care (USDHHS, 2001). Stigma leads a person to believe that those who have mental illness are inferior to "normal" people, prompting families to hide its mentally ill patients from society (Ward \& Heidrich, 2009). Ward and Heidrich (2009) found that $63 \%$ of African Americans believed depression to be a personal weakness, and only 31\% believed depression was a health problem. As a group, African Americans have a somatization rate of $15 \%$ while it is only $9 \%$ among Caucasian Americans. This difference speak volumes on the types of utilization and access to care of mental health services by African Americans. African Americans are less likely to receive accurate diagnoses of mental health services than Caucasians and socioeconomic circumstances such as their social standing, historical and present experiences, and other risk factors all lead to underutilization of mental health services and treatments. The cultural 
biases against the (western) concept of mental health and distrust of mental health professionals, coupled with lack of representation, historical mistreatments and disadvantages are important factors that hinder this group from good mental health care. According to the National Alliance for the Mentally Ill (NAMIa, n.d.), of the mental health professionals, only two (2) percent of psychiatrists, two (2) percent of psychologists, and four (4) percent of social workers in the U.S. are African Americans. Ward and Heidrich (2009) found that African American women believe that mental illness is caused by family-related stress and social stress due to racism, but contrary to prior research, these women believed that treatments can help and that coping strategies could be with the church, prayer, and seeking medical and mental health care. William et al. (2007) found the rate of chronic depression was highest in black groups, 56.5\% in African Americans and 56\% in Caribbean blacks, compared with $38.6 \%$ in whites. While an average of $57 \%$ of white American adults with major depressive disorder (MDD) undergo treatments, only 45\% of African Americans and $24.3 \%$ of Caribbean blacks get treated for MDD. Cook et al. (2014) found that compared to whites, blacks and Latinos had less initiation (starting treatments) and adequacy of care. Whites were 1.5-1.7 times more likely to access or initiate care than blacks and Latinos. Moreover, blacks and Latinos were significantly less likely than whites to have minimally adequate care. Hence, there is clear evidence that disparities in treatments in mental health for African Americans compared to white Americans.

\subsection{Native Americans and Alaska Natives}

A relatively small group in the U.S., composing of just under two percent (1.7), Native Americans and Alaska Natives (Census, 2010d) tends to fall off the radar. Compared to other ethnic groups in the U.S., the least is known about Native Americans and mental illness. The Surgeon General's report on mental health (USDHHS, 2001) repeatedly emphasized this theme of the lack of information, and it shows in the literature. Due to their unique history in the U.S. with trauma, stigma, displacement, fragmentation, neglect, poverty, and other socioeconomic factors, Native Americans carry a heavy burden when it comes to mental illness (USDHHS, 2001). Nationally, there are 562 unique tribes and distinct cultures and languages which also contribute to barriers to culturally competence mental health service provision (USDHHS, 2001; Manson, 2004; NKI Institute for Psychiatric Research, 2009). For Native Americans, many of the western concepts of mental health did not exist in their language until contacts with whites (Grandbois, 2005). As previously stated, the separation of the concepts of "mental" and "physical" has been the norm in psychiatry, but for Native Americans, the mental and the physical are indistinguishable (Manson, 2004). For this population, to live in health is to live in accordance with moral or behavioral codes and in harmony with one's community. Therefore, Native American's indigenous treatments methods for mental health illness are aimed at bringing back this balance. Unfortunately, the loss of traditional cultures and way of life has resulted in challenges such as the high rates of suicide and increased mental illness and comorbidity for Native Americans. Indeed, the suicide rate in the Native American population is among the highest of all ethnicities, from 1979-1992, the rate was 1.5 the national rate (USDHHS, 2001). In addition, they are overrepresented in other mental health problems such as homelessness, incarceration, trauma, 
and substance abuse. Despite these problems, information about their mental health utilization is virtually non-existent (USDHHS, 2004; Grandboise, 2005; Manson, 2004).

\subsection{Asian Americans}

At 5.6\% of the U.S. population (Census, 2010a), Asian Americans have traditionally relied on family and close-knit kinships for mutual aid and assistance which includes mental health. Similar to other minority groups, mental illness is often seen as spirit possession. In studying Buddhist religious leaders' perceptions of mental health, Nguyen, Yamada, and Dinh (2012) found these religious leaders attributed mental illness as having caused by life stressors, mind-body imbalance, karma, (lack of) virtuous deeds, and spiritual possession. They also cited "messy and overly adorned outer appearance," aggressive and viollent behaviors, and abnormal cognitive functioning as indicators of mental health issues. These religious leaders also admitted that they do not know very much about mental health in general, especially the western notion of mental health. These findings are indicative of how Asian Americans perceive mental illness. Kinzie, Fredrickson, Ben, Fleck, and Karls (1984) found significant discrepancies in concepts of mental health between mental health professionals and Khmer refugees, leading to a disconnect between helpers and clients. Vadiver, Jordan, Keopraseuth, and Yu (1995) found that family empowerment was positively correlated with patient's duration of illness, education level and length of time in the U.S. and that satisfaction with services was positively correlated with family member's level of education in Laotian family members who were caregivers for mentally ill members. Furnham and Malik (1994) compared cross-cultural beliefs about depression between Native Britons and Asian-Britons and found age, cultural values, and beliefs to be important factors on their perception about depression and antidepressive behaviors. They also found positive correlation between acculturation levels and feelings about mental illness use and services. Hence, to really understand mental illness as practiced in the U.S. and the west, one has to be educated and/or have familiarity/experience with it.

For Asian Americans, the persistent perception of being the "model minority" has served as a consistent barrier to mental health utilization. Other factors such as economic and language barriers (especially for Southeast Asians), cultural values, disease, and family honor place high stress for them from assessing mental health services (NAWHO, n.d; USDHHS, 2001). Furthermore, compared to other Asians, Southeast Asians show less benefit from mental health services received (Daley, 2005), especially Cambodians. Sangalang (2012) found positive association between racial discrimination and mental illness in Cambodian students.

The spiritual needs of the elder is a primary factor in determining health-seeking behaviors in Asian Americans. That is, care of elders were seen as a family responsibility and therefore services provided should be family-and home-based rather than using the established institutions such as hospitals and nursing homes (Gerdner, Tripp-Reimer, \& Yang, 2008). McKelvey, Baldassar, Sang, and Roberts (1999) found that Asians are more willing to use mental health services than was previously believed, and that the perceived severity of the problem was a factor in increased help-seeking behaviors. Indeed, contrary to established beliefs, McKelvey, Baldassar, Sang, and Roberts (1999) found Vietnamese parents in 
Australia endorsed high preference for Western practitioners, including mental health treatments and services. Why the discrepancy for the use of mental health services but low utilization in this population? Daley (2005) contended that it might be due to situations that are hypothetical, regarding applying the situation to the "other" and not for themselves. Furthermore, maybe efforts to destigmatize mental health has helped.

\subsection{Hispanic/Latino Americans}

In 2010 Latinos account for 16.3 percent of the U.S. population (Census, 2010c). Latino Americans are identified as a high-risk group for depression, anxiety, and substance abuse and the prevalence of depression is higher in women (46\%) than men (19.6\%) (NAMI Multicultural Action Center, n.d). There are several variables that influence Latino perceptions of mental illness. Many Latinos view physical symptoms more seriously than those associated with mental health. Similar to other ethnic groups, stigma plays a big factor. For Latinos, mental illness signifies weakness of the mind and/or spirit possession. In addition, the cultural characteristics of fatalism, which is the belief in "God's will," spirituality, the belief in supernatural forces causing psychological distress; and familism (which calls for families to take care of their own) all contribute to the low rates of mental health utilization. In addition, socioeconomic circumstances, immigration, acculturation, acculturative stress, and language skills confounds and complicates the issue of mental illness and treatments. The complexity diversity of "Latinos" as a group is also an issue influencing perceptions of mental illness and mental health (Kouyoundjian, Zamboangag, \& Hanson, 2003; USDHHS, 2001).

As a group, the literature is mixed regarding prevalence of Latino mental health problems compared to whites, but their underutilization of mental health services is well-documented (Kouyoundjian, Zamboangag, \& Hanson, 2003; USDHHS, 2001). Noel (2009) found significant differences across different ethnic groups in their likelyhood to seek treatments for depression, but Latinos were more likely to prefer counseling or a single form of treatment over combined treatments methods. Rasmussen (2011) found age, education, and time living in the U.S. to be significant predictors of Latinos' alternative explanations for causes of mental illness. The California Reducing Disparities Project (Aguilar-Gaxiola et al., 2012) and the U.S Surgeon General's report (USDHHS, 2001) pain a bleak picture of Latinos as one of the groups most at risk for mental health and benefits the least from U.S. mental health system.

Education level is positively linked to improved health and mental health (Robert Wood Johnson Foundation, 2009; Dalgard, Mykletun, Rognerud, Johansen, \& Zahl, 2007). Curiously there is relatively few research specifically on the association between education level and attitudes toward mental health services. This can be explained in the fact that educational level is often subsumed into a bigger category of "socioeconomic status." Research has shown that one's socioeconomic status-i.e., educational level-is positively correlated to attitudes toward mental health services (Golberstein, Eisenberg, \& Gollus, 2008; Nguyen, Yamada, \& Dinh, 2012; Urdaneta, Huron, Saldana, \& Winkler, 1995). However, in examining Nepalese immigrants and refugees, Lama (2013) found no differences between 
educational level and attitudes toward mental illness, hence, cultural factors might be at play. In addition to formal educational level attained, the research shows that education about mental health is paramount in trying to eradicate stigma regarding mental health. In fact, in all of the materials on how to de-stigmatize mental illness, educating the public about mental illness is often cited by the leading agencies in the world as the number one strategy (World Health Organization, 2004; NIMH, 2008). Hence, specific education about mental illness is correlated to improved attitudes toward mental health services and treatment.

In summary, for different populations, the literature is clear that race and education play important roles in one's perception toward mental health treatments. The next section describes our study methodology in trying to discern these effects.

\section{Methods}

\subsection{Hypothesis}

Both race and education can influence people's perception toward mental health treatment, but no study in the past has examined the interaction effect between racie and education on perception toward mental health treatment. In this study we postulated that different racial groups would have different perception toward the efficacy of mental health treatments; furthermore, we hypothesize that racial differences in perception toward the efficacy of mental health treatment vary according to educational levels. From the literature, we know that education does not have a same impact on perception of mental health treatment. For example, people with a college education do not necessarily have the similar perception toward mental health treatment across racial groups. Hence, the results of this study could clarify the influences of race and education on perception toward mental health.

\subsection{Data Source and Sample}

This study's sample came from the 2012 Behavioral Risk Factor Surveillance System (BRFSS), an annual survey data initiated by Centers for Disease Control and Prevention (CDC). BRFSS is a system of health-related telephone surveys that collect state data about U.S. residents regarding their health-related risk behaviors, chronic health conditions, and use of preventive services conducted in both English and Spanish. The BRFSS surveys are continuously administered using in-house interviewers or contract with telephone call centers or universities with Random Digit Dialing (RDD) techniques to both landlines and cell phones (CDC, 2014). Landline telephone numbers are stratified as either high density (listed 1+block telephone numbers) or medium density (not listed 1+block telephone numbers) to yield residential telephone numbers. The cellular telephone sample is randomly generated from a sampling frame of confirmed cellular area code and prefix combinations and respondents are randomly selected with equal probability of selection. This study included 93,896 respondents aged 18 and older, with 1,433 American Indians, 1,325 Asians, 3,372 Blacks, 12,546 Hispanics, and 72,829 Whites and the respondents are a representative sample of the respective ethnic groups. 


\subsection{Measures}

\subsubsection{Dependent Variable}

Positive perception towards mental health treatments was measured by the question: "Treatments can help people with mental illness lead normal lives. Do you agree slightly or strongly, or disagree slightly or strongly?” This item has a moderate but significant relationship with the item "People are generally caring and sympathetic to people with mental illness. Do you agree slightly or strongly or disagree slightly or strongly?” (b = .19, $\mathrm{p}<.001$; $95 \%$ C.I. $=.18-.20)$. This result suggests that this variable has good criterion validity. We then coded it as 1 (Agree strongly) and 0 for otherwise. Therefore if the answer was 1, it refers to a positive perception toward the efficacy of mental health treatments and 0 as not positive.

\subsubsection{Independent Variables}

We selected five racial group including Asian Americans, American Indians, Blacks, Hispanics, and Whites. Education was coded a 1 for high school or less, 2 for attended college, and 3 for college graduates.

\subsubsection{Covariates}

Sex was coded 0 for female and 1 for male. Employment status was the independent variable of this study. Respondents' age ranged from 18 to 99 years old. Income brackets ranged from $\$ 15,000$ or less to $\$ 50,000$ or more. Marital status was coded 1 for married/partnered; 2 for divorced, separated, or widowed; and 3 for single never having never been married.

\subsubsection{Data Analysis}

We used logistic regression analysis and tested the interaction effect between race and education on respondents' positive perception towards of mental health treatments. In order to explain the interaction effect, we estimated the predictive margins probability of positive perception toward mental health treatments for each racial group at three levels of education. Furthermore, we used a graph to present the interaction effect (Mitchell, 2012).

\section{Results}

Table 1 presents the descriptive statistics for all variables used in the study by race. In general, Blacks, Asians, American Indians, and Hispanic had a greater negative perception toward the efficacy of mental health treatments than Whites. Asians had a greatest percent of college graduated and American Indians and Hispanics the lowest. Female respondents made up the majority across all racial groups. Asians were the youngest group and Whites the oldest. Hispanics had the lowest average of income and Whites the highest. Blacks had the lowest percent of married and Whites and Asians the highest. The results in Table 1 suggest variations among the five selected racial groups. 
Table 1. Descriptive statistics for selected variables $(\mathrm{N}=93,896)$

\begin{tabular}{llllll}
\hline Variables & $\begin{array}{l}\text { White } \\
(\mathrm{n}=72,829)\end{array}$ & $\begin{array}{l}\text { Black } \\
(\mathrm{n}=3,372)\end{array}$ & $\begin{array}{l}\text { Asian } \\
(\mathrm{n}=1,325)\end{array}$ & $\begin{array}{l}\text { American Indian } \\
(\mathrm{n}=1,433)\end{array}$ & $\begin{array}{l}\text { Hispanic } \\
(\mathrm{n}=12,546)\end{array}$ \\
\hline $\begin{array}{l}\text { Positive perception towards } \\
\text { mental health treatment }\end{array}$ & & & & & \\
$\begin{array}{l}\text { Positive } \\
\text { Negative }\end{array}$ & $68.36 \%$ & $61.69 \%$ & $56.13 \%$ & $57.63 \%$ & $42.36 \%$ \\
\hline $\begin{array}{l}\text { Education } \\
\text { HS and below }\end{array}$ & $31.64 \%$ & $38.31 \%$ & $43.87 \%$ & $42.37 \%$ & $57.64 \%$ \\
$\begin{array}{l}\text { College attended } \\
\text { College graduated }\end{array}$ & $36.09 \%$ & $47.97 \%$ & $24.89 \%$ & $57.12 \%$ & $61.80 \%$ \\
\hline Sex & $33.47 \%$ & $31.74 \%$ & $26.09 \%$ & $29.41 \%$ & $23.68 \%$ \\
Male & $30.04 \%$ & $20.29 \%$ & $49.02 \%$ & $13.47 \%$ & $14.52 \%$ \\
Female & & & & & \\
\hline $\begin{array}{l}\text { Age } \\
\text { (SE) }\end{array}$ & $47.76 \%$ & $44.87 \%$ & $49.95 \%$ & $45.63 \%$ & $48.89 \%$ \\
\hline $\begin{array}{l}\text { Income } \\
\text { (SE) }\end{array}$ & $52.24 \%$ & $55.13 \%$ & $50.05 \%$ & $54.37 \%$ & $51.11 \%$ \\
\hline Marital Status & 49.60 & 44.83 & 40.79 & 45.51 & 42.03 \\
married & $(0.14)$ & $(0.64)$ & $(0.87)$ & $(0.87)$ & $(0.28)$ \\
separated/divorced & 3.94 & 3.10 & 3.92 & 2.81 & 2.55 \\
never married & $(0.01)$ & $(0.06)$ & $(0.08)$ & $(0.08)$ & $(0.03)$ \\
\hline
\end{tabular}

Note: Sample size may vary due to missing data.

The results in Table 2 support the study's hypothesis in that racial differences in positive perception towards mental health treatments varied according to levels of education. In order to clearly delineate how race and education interacted to impact respondents' positive perception towards mental health treatments, we estimated the predictive margins probability of positive perception towards mental health treatments for each racial group across three levels of education as presented in Table 3. The probability of positive perception toward the efficacy of mental health treatments among respondents who had high school and lower ranged from 47\% among Hispanics to 54\% among American Indians, 60\% among Asians, 62\% among Whites, and 64\% among Blacks. The probability of positive perception toward the efficacy of mental health treatments among respondents who attended college ranged from $45 \%$ among Hispanics to 54\% among Asians, 65\% among Blacks, 67\% among; American Indians, and $68 \%$ among Whites. Finally, the probability of positive perception toward mental health treatments among college graduated ranged from 49\% among Hispanics to 63\% among Asians, 66\% among American Indians, 68\% among Blacks, and 75\% among Whites. Figure 1 further illustrates the interaction effect of race and education on positive perception towards of mental health treatments. However the results in Table 2 and Figure 1 do not clearly explain how race and education influenced respondents' positive perception towards mental health treatments. 
Table 2. Logistic regression of positive perception towards mental health treatment with interaction effect between race and education $(\mathrm{N}=93,896)$

\begin{tabular}{lll}
\hline Variable & Odds Ratio & $95 \%$ CI of Odds Ratio \\
\hline Race (ref: White) & & \\
Black & 1.07 & $(0.82,1.39)$ \\
Asian & 0.90 & $(0.49,1.68)$ \\
American Indian & $0.70^{*}$ & $(0.51,0.95)$ \\
Hispanic & $0.53^{* * *}$ & $(0.46,0.61)$ \\
\hline Education (ref: High school and below) & & \\
College attended & $1.30^{* * *}$ & $(1.19,1.42)$ \\
College graduated & $1.90^{* * *}$ & $(1.73,2.07)$ \\
\hline Race\# Education & & \\
Black\# College attended & 0.82 & $(0.57,1.18)$ \\
Black\# College graduated & $0.65^{*}$ & $(0.44,0.96)$ \\
Asian\# College attended & 0.62 & $(0.27,1.40)$ \\
Asian\# College graduated & 0.62 & $(0.31,1.21)$ \\
American Indian\# College attended & 1.41 & $(0.84,2.36)$ \\
American Indian\# College graduated & 0.89 & $(0.45,1.75)$ \\
Hispanic\# College attended & $0.73^{* * *}$ & $(0.59,0.91)$ \\
Hispanic\# College graduated & $0.57^{* * *}$ & $(0.46,0.69)$ \\
\hline
\end{tabular}

Note:

1) *: $\mathrm{p}<0.05 ; * *: \mathrm{p}<0.01 ; * * *: \mathrm{p}<0.001$.

2) Sex, age, income and marital status were controlled.

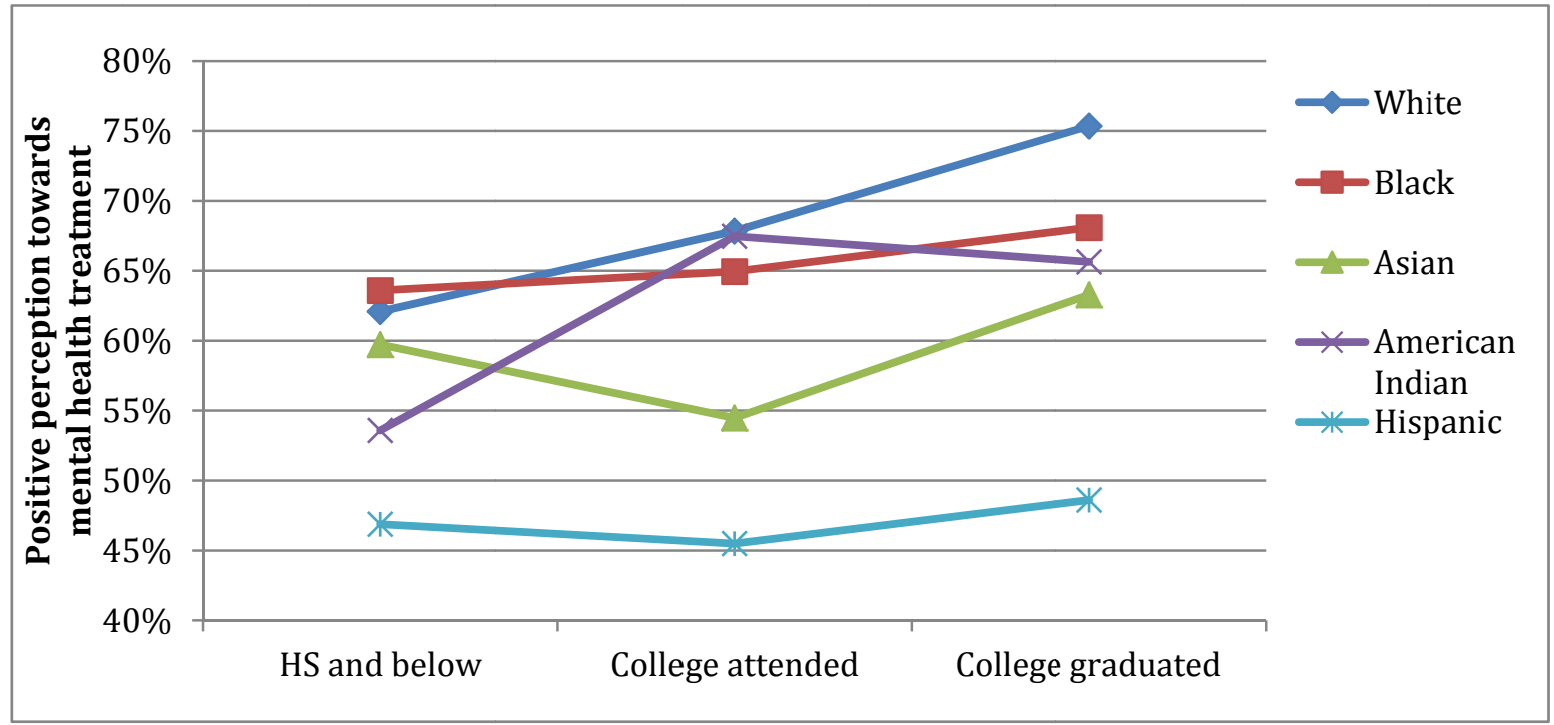

Figure 1. Interaction effect between race and education on positive perception towards mental health treatment 


\section{Macrothink}

We performed a post-hoc comparison using Stata's procedure, "margins r" to test for the statistical significance of the differences of the probability of positive perception towards mental health treatments between racial groups based on education levels. The results are presented in the second part of Table 3. Among 12 pairs of comparison, only seven (7) had a statistical significant difference.

Table 3. Predictive margin of positive perception towards mental health treatment with interaction effect between race and education $(\mathrm{N}=93,896)$

\begin{tabular}{lll}
\hline & Margin & $95 \% \mathrm{CI}$ \\
\hline White \# High school and below & $62 \%^{* * *}$ & $(61 \%, 64 \%)$ \\
White \# College attended & $68 \%^{* * *}$ & $(67 \%, 69 \%)$ \\
White \# College graduated & $75 \%^{* * *}$ & $(74 \%, 76 \%)$ \\
Black \# High school and below & $64 \%^{* * *}$ & $(58 \%, 69 \%)$ \\
Black \# College attended & $65 \%^{* * *}$ & $(59 \%, 70 \%)$ \\
Black \# College graduated & $68 \%^{* * *}$ & $(62 \%, 74 \%)$ \\
Asian \# High school and below & $60 \%^{* * *}$ & $(45 \%, 74 \%)$ \\
Asian \# College attended & $54 \%^{* * *}$ & $(42 \%, 67 \%)$ \\
Asian \# College graduated & $63 \%^{* * *}$ & $(57 \%, 69 \%)$ \\
American Indian \# High school and below & $54 \% * * *$ & $(46 \%, 61 \%)$ \\
American Indian \# College attended & $67 \% * * *$ & $(59 \%, 76 \%)$ \\
American Indian \# College graduated & $66 \% * * *$ & $(52 \%, 79 \%)$ \\
Hispanic \# High school and below & $47 \%^{* * *}$ & $(44 \%, 50 \%)$ \\
Hispanic \# College attended & $45 \%^{* * *}$ & $(42 \%, 49 \%)$ \\
Hispanic \# College graduated & $49 \%^{* * *}$ & $(45 \%, 52 \%)$ \\
\hline Post hoc comparisons & & \\
\hline & Contrast & $95 \% \mathrm{CI}$ \\
\hline (Black vs White) College graduated & $-7 \% *$ & $(-13 \%,-1 \%)$ \\
(Asian vs White) College attended & $-13 \% *$ & $(-26 \%, 0 \%)$ \\
(Asian vs White) College graduated & $-12 \% * *$ & $(-17 \%,-6 \%)$ \\
(American Indian vs White) High school and below & $-9 \%^{*}$ & $(-16 \%,-1 \%)$ \\
(Hispanic vs White) High school and below & $-15 \%^{* * *}$ & $(-19 \%,-12 \%)$ \\
(Hispanic vs White) College attended & $-22 \% * * *$ & $(-26 \%,-18 \%)$ \\
(Hispanic vs White) College graduated & $-26 \%^{* * *}$ & $(-30 \%,-22 \%)$ \\
\hline
\end{tabular}

Note:

1) *: $\mathrm{p}<0.05 ; * *: \mathrm{p}<0.01 ; * * *: \mathrm{p}<0.001$.

2) Only significant differences are reported in the post hoc comparisons.

Among respondents who only had a high school education or less, American Indians had a probability of $9 \%$ lower in their positive perception towards mental health treatments than White, and Hispanics had a probability of $15 \%$ lower in their positive perception toward 
mental health treatments than Whites.

Among respondents who attended college, Asians had a probability of $13 \%$ lower in their positive perception toward mental health treatments than Whites, and Hispanics had a probability $22 \%$ lower in their positive perception toward mental health treatments than Whites.

Among respondents who graduated from college, Blacks had a probability of $7 \%$ lower in their positive perception toward mental health treatments than Whites, Asians had a probability of $12 \%$ lower in their positive perception toward the efficacy of mental health treatments than Whites, and Hispanics had a probability of $26 \%$ lower than Whites.

\section{Conclusion and Implication}

The finding of this study can be summarized that after controlling for key demographic variables such as sex, age, income, and marital status, race does influence people's positive perception towards mental health treatments, but it also appears that education moderates the association between race and positive perception towards mental health treatments. The results of this study revealed that racial differences and positive perception of mental health treatments were found at some levels of education but not all. White college graduates were more likely to be positive towards mental health treatments than Asian, Black, and Hispanic college graduates. Surprisingly, there was no statistically significant difference between American Indian college graduates compared to White college graduates. The interaction effect is clearly revealed in the differences in such the way that among high school graduates or less, only American Indians and Hispanics had statistical significant difference in positive perception towards mental health treatments compared to Whites. The difference between Hispanics and Whites was 1.6 times greater than that between American Indians and Whites. Among respondents who attended college, only Asians and Hispanics had lower positive perception towards mental health treatments than Whites. However the difference between Hispanics and Whites was 1.83 times greater than between Asians and Whites. The difference in the probability of positive perception towards mental health treatments between Hispanic college graduates and White college graduate was more than twice the difference of that between Asians and Whites, and 3.71 times the difference between Blacks and Whites.

All things considered, Hispanics at all levels of education had lower positive perception towards mental health treatments than Asians, American Indians, Blacks and Whites. On the other hand, White college graduates had the greatest positive perception towards mental health treatments. Overall, respondents with a college education tend to be more positive toward mental health treatments. Thus education seems to be a key factor influencing respondents' positive perception towards mental health treatments. This result is consistent with previous research (Pote \& Orrell, 2002; Vadiver, Jordan, Keopraseuth, \& Yu, 1995; Rasmussen, 2011; Robert Wood Johnson Foundation, 2009; Dalgard, Mykletun, Rognerud, Johansen, \& Zahl, 2007; Urdaneta, Huron, \& Winkler, 1995) and provides a key to future efforts at increasing utilization of mental health treatment and services.

The research in the effectiveness of mental health treatments is also promising. The flowering 
of many evidence-based collaboratives such as the Cochrane Collaboration, and SAMHSA's National Registry of Evidence-based Programs and Practices are encouraging. One example is the application of cognitive behavioral therapy on a multitude of mental health issues (http://www.samhsa.gov/ebp-web-guide). Indeed, the Centers for Disease Control, in collaboration with other federal agencies, compiled a comprehensive report entitled "Attitudes Toward Mental Illness: Results from the Behavioral Risk Factor Surveillance System" (CDC el al., 2012) which found that more than $80 \%$ of adults agreed that treatment is effective, with those receiving mental health services were more likely to agree that treatment is effective. Furthermore, they found that when more funding is allotted, mental health utilization increases.

Health education programs can also help to improve public attitudes toward mental illness and mental illness treatments (Jorm, 2000). In order to change people's negative perception toward mental health treatments, public health education programs should target different racial communities with different educational strategies and programs. Pillot testing of public education programs should be evaluated by both quantitative and qualitative approaches prior to any policy implications. The literature on mental health education clearly delineates that to be successful, these programs have to be culturally meaningful and accessible. Primary care physicians, social workers, and public health professionals also play an important role in changing clients' negative perception towards mental illness and mental illness treatments since they are often viewed as experts and routinely provide guidance and education to the public.

A key limitation of this study is the measurement of positive perception towards mental health treatments. This measure appears broad therefore it's difficult to distinguish respondents' perceived efficacy of specific types of treatment whether they are medical or psycho-social treatments. Nevertheless, the results are important for the effort to improve public attitudes towards mental illness and mental illness treatments with respect to racial and educational diversity. For effective public mental health education and intervention program developments, future studies should explore public attitudes toward specific types of mental health treatments.

\section{References}

Aguilar-Gaxiola, S., Loera, G., Méndez, L., Sala, M., Latino Mental Health Concilio, \& Nakamoto, J. (2012). Community-Defined Solutions for Latino Mental Health Care Disparities: California Reducing Disparities Project, Latino Strategic Planning Workgroup Population Report. Sacramento, Ca: UC Davis.

Caribbean Blacks, and non-Hispanic whites. Archives of General Psychiatry, 64(3), 305-315.

CDC et al. (2012). Attitudes Toward Mental Illness: Results from the Behavioral Risk Factor Surveillance System. Atlanta (GA); Centers for Disease Control and Prevention. Retrieved from http://www.cdc.gov/hrqol/Mental_Health_Reports/pdf/BRFSS_Report_InsidePages.pdf

Census 2010a. (2012). The Asian population, 2010. Retrieved from: http://www.census.gov/prod/cen2010/briefs/c2010br-11.pdf 
Census 2010b. (2011). The black population, 2010. Retrieved from: http://www.census.gov/prod/cen2010/briefs/c2010br-06.pdf

Census 2010c. (2011). The Hispanic population, 2010. Retrieved from: http://www.census.gov/prod/cen2010/briefs/c2010br-04.pdf

Census 2010d. (2012). The Native American and Alaska Native population, 2010. Retrieved from: http://www.census.gov/prod/cen2010/briefs/c2010br-10.pdf

Census 2010e. (2011). The White population, 2010. Retrieved from http://www.census.gov/prod/cen2010/briefs/c2010br-05.pdf

Cook, B. L., Zuvekas, S. H., Carson, N., Wayne, G. F., Vesper, A., \& McGuire, T. G. (2014). Assessing racial/ethnic disparities in treatments across episodes of mental health care. Health Services Research, 49(1), 206-229. http://dx.doi.org/10.1111/1475-6773.12095

Dalgard, O. S., Mykletun, A., Rognerud, M., Johansen, R., \& Zahl, P. H. (2007). Education, sense of mastery and mental health: Results from a nation wide health monitoring study in Norway. BMC Psychiatry, 7(20), 1-9. http://dx.doi.org/10.1186/1471-244X-7-20

Daley, T. C. (2005). Beliefs about treatments of mental health problems among Cambodian American children and parents. Social Sciences \& Medicine, 61, 2384-2395. http://dx.doi.org/10.1016/j.socscimed.2005.04.044

Furnham, A., \& Malik, R. (1994). Cross-cultural beliefs about “depression." The International Journal of Social Psychiatry, 40(2), 106-123. http://dx.doi.org/10.1177/002076409404000203

Gerdner, L. A., Tripp-Reimer, T., \& Yang, D. (2008). Perception and care of elder Hmong Americans with chronic confusion or tem toob. Hallym International Journal of Aging, 10(2), 111-138. http://dx.doi.org/10.2190/HA.10.2.d

Georgiades, K., Boyle, M. H., \& Fife, K. A. (2013). Emotional and behavioral problems among adolescent students: The role of immigrant, racial/ethnic congruence and belongingness in school. Journal of Youth Adolescence, 42, 1473-1492. http://dx.doi.org/10.1007/s10964-012-9868-2

Golberstein, E., Eisenberg, D., Gollust, S., E. (2008). Perceived stigma and mental health care seeking. Psychatric Services, 59(4), 392-399. http://dx.doi.org/10.1176/ps.2008.59.4.392

Grandbois, D. (2005). Stigma of mental illness among American Indian and Alaska Native nations: Historical and contemporary perspectives. Issues in Mental Health Nursing, 26, 1001-1024. http://dx.doi.org/10.1080/01612840500280661

Kinzie, J. D., Fredrickson, R. H., Ben, R., Fleck, J., \& Karls, W. (1984). Posttraumatic stress disorder among survivors of Cambodian concentration camps. American Journal of Psychiatry, 141, 645-650. http://dx.doi.org/10.1176/ajp.141.5.645

Kleinman, A. (1976). Culture, illness and care: Clinical lessons from anthropologic and cross-cultural research. Annals of Internal Medicine, 88, 251-258. 
http://dx.doi.org/10.7326/0003-4819-88-2-251

Kouyoumdjian, H., Zamboanga, B. L., \& Hanson, D. J. (2003). Barriers to community mental health services for Latinos: Treatments considerations. Faculty publications, department of psychology. Paper 128. Retrieved from http://digitalcommons.unl.edu/psychfacpub/128

Krol, L. (2011). The relationship of culture and the stigma of mental illness (Doctoral Disseration). Retrieved from ProQuest. AAI3429143.

Laditka, J. N., Laditka, S. B., Liu, R., Price, A. E., Wu, B., Friedman, D. B., ... Losdon, R. G. (2011). Older adults' concerns about cognitive health: Commonalities and difference among six United States ethnic groups. Aging \& Society, 31, 1202-1228. http://dx.doi.org/10.1017/S0144686X10001273

Lama, S. (2013). Attitudes and perceptions of mental disorders among individuals from Nepal. Master of social work clinical research papers. Paper 220. Retrieved from http://sophia.stkate.edu/msw_papers/220

Jorm, A. F. (2000). Mental health literacy Public knowledge and beliefs about mental disorders. The British Journal of Psychiatry, 177(5), 396-401. http://dx.doi.org/10.1192/bjp.177.5.396

Lopez, P. L. (2009). Immigration experience and subsequent mental health issues in immigrant children from China, Russia, and the Dominican Republic: Implications for the use of cross-cultural comparisons (Doctoral Dissertation). Retrieved from ProQuest. LLC. 3377716.

Manson, S. M. (2004). Meeting the mental health needs of American Indians and Alaska Natives. USDHHS. Retrieved from: http://www.nasmhpd.org/docs/publications/archiveDocs/2004/native\%20american\%20FINA L-04.pdf

McKelvey, R. S., Baldassar, L. V., Sang, D. L., \& Roberts, L. (1999). Vietnamese parental perceptions of child and adolescent mental illness. Journal of the Americam Academy of Child $\begin{array}{llll}\text { and } \quad \text { Adolescent } & \text { Psychiatry, } & \text { 38(10), }\end{array}$ http://dx.doi.org/10.1097/00004583-199910000-00020

Mitchell, M. N. (2012). Interpreting and visualizing regression models using Stata. Stata Press books.

Nakashima, K., Isobe, C., \& Ura, M. (2013). How does higher in-group social value lead to positive mental health? An integrated model of in-group identification and support. Asian Journal of Social Psychology, 16, 271-278. http://dx.doi.org/10.1111/ajsp.12031

NAMIa. (n.d). African American community mental health fact sheet. Retrieved from http://www.nami.org/Template.cfm?Section=Fact_Sheets1\&Template=/ContentManagement/ ContentDisplay.cfm\&ContentID $=53812$

NAMI Multicultural Action Center. (n.d.). Latino community mental health fact sheet. 
Retrieved

from

http://www.nami.org/Content/NavigationMenu/Find_Support/Multicultural_Support/Annual_ Minority_Mental_Healthcare_Symposia/Latino_MH06.pdf

NAWHO. (n.d.). Mental health and depression in Asian Americans. Retrieved from http://www.hawaii.edu/hivandaids/Mental_Health_and_Depression_in_Asian_Americans.pdf

NIMH. (2008). The national institute of mental health strategic plan. Retrieved from http://www.nimh.nih.gov/about/strategic-planning-reports/index.shtml\#strategic-objective4

NKI for Psychiatric Research. (2009). Native Americans. Retrieved from http://ssrdqst.rfmh.org/cecc/index.php?q=node/22

Noel, L. T. M. (2009). Causal beliefs and treatments preferences for the symptoms of depression among chronically ill African American, Latino, and White patients (Doctoral Dissertation). Retrieved from ProQuest. AAI3347805.

Nguyen, H. T., Yamada, A. M., \& Dinh T. Q. (2012). Religious leaders' assessment and attribution of the causes of mental illness: An in-depth exploration of Vietnamese American Buddhist leaders. Mental Health, Religion, \& Culture, 15(5), 511-527. http://dx.doi.org/10.1080/13674676.2011.594037

Parra, F. (1988). Perceptions of mental illness among Mexican-Americans: The influence of education. Sociologia Internationalis, 26(1), 85-93.

Pescosolido, B. A., Martin, J. K., Link, B. G., Kikuzawa, S., Burgos, G., Swindle, R., \& Phelan, J. (1999). Amerrican's views of mental health and illness at century's end: Continuity and change. Indiana Consortium for Mental Health Services Research.

Pote, H. L., \& Orrell, M. W. (2002). Perceptions of schizophrenia in multi-cultural Britain. Ethnicity \& Health, 7(1), 7-20. http://dx.doi.org/10.1080/13557850220146i966

Rasmussen, F. O. (2011). Cultural definitions of emotional problems: Impact on problem experience, care seeking, sources of care, and satisfaction with care among Latino community members living in the United States (Doctoral Dissertation). Retrieved from ProQuest. UMI3474901.

Robert Wood Johnson Foundation. (2009). Education matters for health. Robert Wood Johnson Foundation. Retrieved from http://www.rwjf.org/content/dam/farm/reports/issue_briefs/2011/rwjf70447

Sangalang, C. C. (2012). Racial discrimination, ethnic identity, and depression among Cambodina American adolescents (Doctoral Dissertation). Retrieved from ProQuest. UMI3523476.

Stickney, S., Yanosky, D., Black, D. R., \& Stickney, N. (2012). Socio-demographic variables and perceptual moderators related to mental health stigma. Journal of Mental Health, 21(3), 244-256. http://dx.doi.org/10.3109/09638237.2012.670878

Sue, S., Wagner, N., Ja, D., Margullis, C., \& Lew, L. (1976). Conceptions of mental illness 


\section{Macrothink}

International Journal of Social Science Research

ISSN 2327-5510

2015, Vol. 3, No. 2

among Asian and Caucasian-American students. Psychological Reports, 38, 703-708. http://dx.doi.org/10.2466/pr0.1976.38.3.703

Tanenbaum, S. J. (2009). Psychiatrist-consumer relationship in U.S. public mental health care: consumers' views of a disability system. Disability \& Society, 24(6), 727-738. http://dx.doi.org/10.1080/09687590903160225

Urdaneta, M. L., Huron Saldan, D., Winkler, A. (1995). Mexican-American perceptions of severe mental illness. Human Organization, 54(1), 70-77.

U.S. Dept. of Health and Human Services. (1999). Mental health: A report of the surgeon general. Rockville, MD: US Dept. of HHS, Public Health Service, Office of the Surgeon General.

U.S. Dept. of Health and Human Services. (2001). Mental health: Culture, race, and ethnicity-A supplement to mental health: A report of the surgeon general. Rockville, MD: US Dept. of HHS, Public Health Service, Office of the Surgeon General.

Vandiver, V. L., Jordan, C., Keopraseuth, K., \& Yu, M. (1995). Family empowerment and service satisfaction: An exploratory study of Laotian families who care for a family member with mental illness. Psychiatric Rehabilitation Journal, 19(1), 47-54. http://dx.doi.org/10.1037/h0095460

Ward, E. C., \& Heidrich, S. M. (2009). African American women's beliefs above mental illness, stignma, and preferred coping behaviors. Research in Nursing \& Health, 32(5), 480-492. http://dx.doi.org/10.1002/nur.20344

Williams, D. R., Gonzales, H. M., Neighbors, H., Nesse, R., Abelson, J., Sweekman, J., \& Jackson, J. H. (2007). Prevalence and distribution of major depressive disorder in African Americans. http://dx.doi.org/10.1001/archpsyc.64.3.305

World Health Organization. (2004). Promoting mental health: Concepts, emerging evidence, practice. World Health Organization, France.

\section{Copyright Disclaimer}

Copyright for this article is retained by the author(s), with first publication rights granted to the journal.

This is an open-access article distributed under the terms and conditions of the Creative Commons Attribution license (http://creativecommons.org/licenses/by/3.0/). 